OSSIÊ 


\section{Um Mundo em Recomposição: Uma Análise Antropológica das Novas Formas de Regulação e Certificação de Objetos e Pessoas na Contemporaneidade}

\section{A World in Recomposition: An Anthropological Analysis of New Forms of Regulation and Certification of Objects and People in Contemporaneity}

\section{Hully Guedes Falcão}

Programa de Pós-graduação em Informação e Comunicação em Saúde, Fundação Oswaldo Cruz, Rio de Janeiro, RJ, Brasil

\section{Fabio Reis Mota}

Programa de Pós-graduação em Antropologia, Universidade Federal Fluminense, Niterói, Rio de Janeiro, Brasil

\section{Manuela Vieira Blanc}

Departamento de Ciências Sociais, Universidade Federal do Espírito Santo, Goiabeiras, Vitória, Espírito Santo, Brasil

\section{Gabriela de Lima Cuervo}

Secretaria de Educação do Rio de Janeiro, Rio de Janeiro, RJ, Brasil

\section{RESUMO}

Neste dossiê, apresentamos pesquisas qualitativas e, especialmente, etnografias que colocam sob descrição e análise os mecanismos de controle, certificação e reconhecimento dos bens materiais e humanos nas sociedades contemporâneas por meio de novas formas de classificação existentes atualmente. Ao trazer sob exame este movimento padronizador dos mecanismos e critérios de conformação destas arenas públicas, o olhar antropológico se apresenta como uma ferramenta fundamental para avançar em direções que permitam desvelar as diferentes articulações, adequações, composições e ressignificações acerca dessas normatividades estandardizadas. Neste sentido, os artigos apresentados evidenciam controvérsias envolvendo grupos que criam críticas e justificações para aderir, denunciar e se reapropriar destas regulações, a partir de seus próprios esquemas cognitivos e culturais $\mathrm{O}$ texto de apresentação se organizará da seguinte maneira: na primeira parte discorremos sobre como nos aproximamos da temática a partir da construção de redes e intercâmbios acadêmicos, para depois desenvolvermos e explicarmos no que consiste a governança pela norma ou por standards. Após esse exercício de contextualização, discutimos como essas questões se apresentam no âmbito das classificações e avaliações 
que envolvem a produção de conhecimento científico e a conformação de mercados e, também, no contexto urbano, através da padronização do espaço público e de controle das pessoas.

Palavras-chave: Standards, Padronização, Controle, Classificações, Espaço Urbano.

\section{ABSTRACT}

In this dossier, we present qualitative research and, especially, ethnographies that describe and analyze the mechanisms of control, certification and recognition of material and human goods in contemporary societies through new forms of classification. By bringing under examination this standardizing movement of the mechanisms and criteria of conformation of these public arenas, the anthropological look presents itself as a fundamental tool to advance in directions that allow the unveiling of the different articulations, adaptations, compositions, re-significations about these standardized normativities. In this sense, the articles presented show controversies involving groups that create critiques and justifications to adhere, denounce and re-appropriate these regulations, from their own cognitive and cultural schemes. The presentation text will be organized as follows: in the first part we will discuss how we approached the theme by building networks and academic exchanges, and then we will develop and explain what governing by standards consists of. After this contextualization exercise, we discuss how these issues present themselves in the scope of classifications and evaluations that involve the production of scientific knowledge and the conformation of markets, and also in the urban context, through the standardization of public space and the control of people.

Keywords: Standards, Standardization, Control, Classifications, Urban Space.

O trabalho de pesquisa no domínio das Ciências Sociais requer a cooperação contínua, a circulação e a interlocução entre cientistas sociais de vários países, abrigando não somente a heterogeneidade linguística e cultural, mas também a diversidade de instrumentos analíticos, metodológicos e epistemológicos conformados nas distintas tradições acadêmicas. Esse é o meio mais eficiente para se neutralizar os "xamanismos sociológicos", da ordem das profecias fáceis, e potencializar o alargamento dos horizontes acerca da compreensão dos fenômenos sociais com os quais trabalhamos: olhando o global, expandido e implodindo as fronteiras a partir dos materiais empíricos e etnográficos que as pesquisas nos fornecem in loco, para além de respostas fáceis, perguntas constantes.

Desse modo, podemos aperfeiçoar as ferramentas analíticas e metodológicas 
manuseadas nos universos empíricos nos quais mergulhamos para renovarmos as análises e as interpretações forjadas pelo nosso trabalho de tessitura das "evidências simbólicas" (CARDOSO DE OLIVEIRA, 2018). Evidências não nos termos do direito positivista, espaço de lugar das "verdades encapsuladas", mas na acepção etimológica mais pura, o de evidentia, clareza, transparência daquilo que vem de dentro para fora. Afinal, é nesse ir e vir entre dados etnográficos, estatísticos, históricos, demográficos, narrativas, quadros de memórias, teorias diversas etc., que se entremeiam com as perspectivas e biografias, sentimentos e emoções, razão e compreensão, que o trabalho do artesanato do social concede forma: as teorias nas prateleiras e os dados nas nuvens dispersas desse complexo universo do fazer sociedade.

Desse modo, o trabalho cooperativo, internacional e pautado pela convivialidade respeitosa, humana e amigável é um dos meios mais eficientes para que possamos nos confrontar diuturnamente com outras visões, perspectivas, condições sociais e históricas que emergem aos olhos dos cientistas sociais. Isso nos ajuda, a nós cientistas sociais, conferir maior substância ao trabalho comparativo e contrastivo, caro ao domínio da Antropologia e Sociologia. O Programa de Pós-Graduação em Antropologia da Universidade Federal Fluminense (PPGA/UFF) - e muitos dos seus núcleos de pesquisa, em especial o Núcleo Fluminense de Estudos e Pesquisa (NUFEP), o Instituto Nacional de Ciência e Tecnologia - Instituto de Estudos Comparados em Administração Institucional de Conflitos (INCT-InEAC) - tem sido um lugar privilegiado de experimentação de métodos e pesquisas comparativas entrelaçando diversas correntes das Sociologias e Antropologias levadas a cabo no Brasil e no exterior.

Desde o final dos anos 90 do século XX, sociólogos, antropólogos brasileiros e franceses encamparam um projeto acadêmico e institucional que conferiu argamassa a uma cooperação muito proveitosa e frutífera entre pesquisadores e pesquisadoras dos dois lados do Atlântico. Ele se justificou pelo interesse comum dos grupos do Brasil e da França em torno de eixos temáticos que se articulavam em diferentes linhas e perspectivas de pesquisa empírica.

Indiretamente, nosso dossiê é tributário dessas primeiras estradas abertas com o nascimento de um programa de pesquisa deflagrado e desenvolvido sob os auspícios do Programa CAPES/Cofecub ${ }^{1}$, inicialmente coordenado pelos professores Roberto Kant de Lima (Universidade Federal Fluminense) e Isaac Joseph (Université de Paris X-Nanterre) esse último vindo, infelizmente, a falecer durante a vigência do referido convênio, sendo de comum acordo substituído, posteriormente, pelo professor Daniel Cefaï, também ele, à época,

1 Convênio CAPES/Cofecub n ${ }^{\circ}$ 240/98-I Espaços Públicos: conflitos e democracia em uma perspectiva comparada e o Convênio Capes-Cofecub no 447/04 Sociologia da experiência privada e pública no Brasil e na França. A república no cotidiano: conflitos sociais, ações coletivas, engajamentos associativos e provas pessoais. 
professor da Université de Paris X-Nanterre ${ }^{2}$. Anos depois, já em 2010, outro Capes-Cofecub foi desenvolvido a partir da cooperação entre a École des Hautes Études em Science Sociales (EHESS), tendo como coordenador Laurent Thévenot, do lado francês, e a UFF, coordenado do lado brasileiro, por Marco Antônio da Silva Mello ${ }^{3}$. Além disso, este dossiê resulta diretamente do Programa Capes PRINT da UFF, coordenado por Fabio Reis Mota e co-coordenado por Roberto Kant de Lima, no qual reúne alguns dos pesquisadores que figuram nesse programa de pesquisa internacional.

Esses dispositivos institucionais de cooperação internacional foram fundamentais para que professores e professoras de ambos os países, assim como estudantes de doutorado dos dois lados do Atlântico, realizassem missões de trabalho, bolsas de doutorado sanduíche na França e, igualmente, permitiu que os franceses viessem ao Brasil ${ }^{4}$. Da mesma forma, foram conjugados os interesses etnográficos e analíticos que viabilizaram a publicação dos trabalhos em revistas brasileiras, estrangeiras e em livros organizados na França, Brasil, dentre outros

2 Uma das primeiras atividades deste convênio consistiu na vinda do professor Isaac Joseph à UFF, em Niterói, em abril de 1998. Na ocasião, além de ministrar palestras na UFF e no IUPERJ-UCAM - à época parceiro no projeto CAPES/Cofecub -, reuniu-se por diversas vezes com as equipes do PPGA (naquele então PPGACP), do NUFEP/ UFF e do Laboratório de Etnografia Metropolitana (LeMetro/UFRJ). Um dos primeiros e mais importantes frutos dessa cooperação foi, no entanto, o Colóquio realizado no Centro Internacional de Cerisy-la-Salle no período de 12-19 de junho de 1999, sendo, pois, um dos momentos seminais do Convênio. Na ocasião, o Colloque Cultures civiques et démocraties urbaines reuniu mais de 40 participantes, dentre eles os brasileiros, apresentando seus trabalhos e discutindo suas pesquisas, cujos resultados foram publicados em livro organizado por Daniel Cefaï e Isaac Joseph, intitulado L'Héritage du pragmatisme. Conflits d'urbanité et épreuves de civisme, Editions de l'Aube, 2002. E no Brasil, um dos frutos mais substantivos dessa cooperação desembocou na publicação do livro CEFAI, D.; MELLO, M. A.; MOTA, F. R.; BEROCAN, F. (org.). Arenas públicas: por uma etnografia da vida associativa. Niterói: Eduff, 2011.

3 Projeto Capes COFECUB Regimes de Engajamento Particulares e Universais em Sociedades Plurais: processos de administração institucional de conflitos, ações coletivas e demandas de direitos e reconhecimento em perspectiva comparada (Brasil/França). CAPES-COFECUB n. 694/10. Diversos estudantes de doutorado do PPGA (e do antigo PPGACP) da UFF foram beneficiados com os recursos desse projeto, realizando seus estágios de doutorado sanduíche sob a supervisão de Daniel Cefai e seguindo sistematicamente os seminários de Laurent Thévenot na EHESS. Foram eles: Patricia de Araújo Brandäo, Katia Sento Sé Mello, Soraya Simões, Fabio Reis Mota e Letícia de Luna Freire. Anos depois, outras alunas de doutorado foram beneficiadas com a bolsa sanduíche: Yolanda Gaffrée Ribeiro e Daniela Velasquez Peláez, supervisionadas por Laurent Thévenot, e a última também por Monica Schunp, da EHESS. Essa última aluna foi beneficiada com recursos do Projeto Capes Print mencionado aqui na apresentação.

4 Da mesma forma, Laura Graziela Gomes e Marco Antonio da Silva Mello realizaram seus pós-doutorados no contexto do Programa Capes Cofecub, bem como outros professores puderam realizar missões de trabalho na França, como Roberto Kant de Lima, Delma Pessanha e Felipe Berocan (esse ainda como aluno de mestrado). E diversos pesquisadores da Franca estiveram em missäo de trabalho em Niterói, na UFF, tais como Isaac Joseph, Daniel Cefai, Martine Segalen, Marc Breviglieri, Luca Pattaroni, Laurent Thévenot, Mathieu de Castelbajac, René Levy, Antoine Garapon. Alain Battegay, Pedro Garcia Sanchez, Agnës Deboulet, Dejan Dimitrijevic, Anne Raulin, Marc Bordigoni, Luc Boltanski, Arnaud Esquerre, Jean-Samuel Bordreuil dentre outros 
países $^{5}$. Tais convênios, ainda, permitiram ampliar as interlocuções com os colegas portugueses na ocasião em que o professor José Resende, na época professor da Universidade Nova de Lisboa, e atualmente catedrático da Universidade de Évora, encontrava-se realizando o seu pósdoutorado no extinto Groupe de Sociologie Politique et Moral (GSPM) em estreito diálogo com Luc Boltanski e Laurent Thévenot. O encontro do referido professor com os, então, bolsistas de doutorado sanduíche do Convênio Capes COFECUB, Fabio Reis Mota e Letícia de Luna Freire, hoje, professores, respectivamente, da UFF e da Universidade do Estado do Rio de Janeiro (UERJ), deu lugar a outro estágio dessa interlocução internacional. Meses depois, o professor José Resende, com a ajuda de sua equipe de pesquisa, na ocasião formada por Bruno Dionísio, Alexandre Martins, Catarina Delaunay, Pedro Caetano, dentre outros, organizou um colóquio na Universidade Nova de Lisboa, tendo como convidados do Brasil os professores Roberto Kant de Lima e Marco Antônio da Silva Mello, assim como os dois estudantes brasileiros mencionados acima do Convênio Capes Cofecub que já estavam na França.

Logo, uma cooperação bilateral foi desenvolvida entre Portugal e Brasil através de outro instrumento institucional fomentado pela Coordenação de Aperfeiçoamento de Pessoal de Nível Superior (CAPES) e a Fundação para a Ciência e Tecnologia (FCT), a partir da aprovação do Programa Internacional financiado pelas duas referidas instituições e coordenado pelos professores José Resende, do lado português, e Roberto Kant de Lima e Fabio Reis Mota, do lado brasileiro. Assim como no caso do CAPES/Cofecub, inúmeras atividades foram desenvolvidas com a publicações de artigos em revistas brasileiras e estrangeiras, livros organizados, organização de grupos de trabalho, mesas- redondas nas Reuniões da Associação Brasileira de Antropologia, nas Reuniões de Antropologia do Mercosul, no Congresso Luso-Afro Brasileiro, na International Sociological Association, dentre outros espaços de interlocução fornecidos pelos seminários internos organizados na UFF, na EHESS e na Universidade Nova de Lisboa e, posteriormente, na Universidade de Buenos Aires com a integração do professor Gabriel Nardacchione e de seu grupo de pesquisa, vinculado ao Centro Gino Germani da Universidade de Buenos Aires, a esta rede ampla e heterogênea.

Sendo assim, um trabalho cooperativo que havia se iniciado bilateralmente entre Brasil

\footnotetext{
5 Ver, por exemplo, De la Justification, de Luc Boltanski e Laurent Thévenot, pela a Editora da UFRJ em 2020 ("De la justification: o resplandecimento de um novo gesto pragmático na sociologia francesa"). Disponível em: https:// periodicos.uff.br/antropolitica/article/view/41954. Acesso em: 13 jul. 2021; introdução de dossiê elaborado por Marc Breviglieri, Gabriel Nardacchione e Paola Dias publicado em 2018 na revista francesa Sociologies (L'expérience latino-américaine de la sociologie pragmatique francofone. Élargissement d'un horizon d'analyse? Disponível em: https://journals.openedition.org/sociologies/6174. Acesso em: 13 jul. 2021); e artigo de autoria de Laurent Thévenot no Journal du MAUSS. Disponível em: https://www.journaldumauss.net/?Complement-du-no56-Lagrande-decentration. Acesso em: 13 de jul. 2021.
} 
e França foi ganhando novos contornos com a integração de pesquisadores portugueses, argentinos, assim como mexicanos, suíços, chilenos etc. Em 2018, a aprovação de um Convenio Capes PRINT, como mencionamos, forjou os meios de amalgamar essa extensa rede e ainda ampliá-la para outros países e tradições socioantropológicas ${ }^{6}$.

O trabalho em rede, igualmente, alimentou a elaboração do presente dossiê, pois o organizador e as organizadoras são tributários dos diálogos tecidos ao longo desses anos entre pesquisadores e pesquisadoras da Universidade Estadual do Norte Fluminense Darcy Ribeiro (UENF), localizada no município de Campos dos Goytacazes, através, em especial, das figuras de Arno Vogel, Lana Lage e Wania Mesquita. Duas das organizadoras desse dossiê realizaram suas graduações em Ciências Sociais na UENF (Manuela Blanc e Hully Falcão) e outro organizador trabalhou como professor substituto na mesma instituição (Fabio Reis), tendo suas trajetórias atravessadas nesse espaço acadêmico. Essas cooperações foram desenvolvidas a partir de conversações e projetos comuns realizados em parceria com colegas do campus da UFF localizado na mesma cidade, sobretudo com a professora Jussara Freire, que veio, aliás, ainda como estudante de mestrado para o Brasil por meio do seu então orientador Isaac Joseph, já mencionado mais acima. Uma das organizadoras do dossiê "Um mundo em recomposição: uma análise antropológica das novas formas de regulação e certificação dos objetos e pessoas na contemporaneidade", Manuela Blanc, esteve na UFF como professora substituta e Fabio Reis como é professor adjunto na mesma instituição. De certo ponto de vista, todos e todas estavam gravitando em torno do Programa de Pós-Graduação em Antropologia e do Núcleo Fluminense de Estudos e Pesquisa, fundados em 1994, bem como do INCT-InEAC fundado mais tardiamente, em $2009^{7}$.

Portanto, este Dossiê é resultado de um trabalho em rede, nutrido por um espírito simétrico no qual as colaborações rompem com as tradicionais operações de divisão social científica em que a Europa produz as teorias e a periferia as consome. Pelo contrário, nossos grupos têm se empenhado em desenvolver medidas e instrumentos que viabilizem o entrecruzamento

\footnotetext{
6 Cabe mencionar que esta interlocução resultou no convite formulado, em 2007, por Luis Roberto Cardoso de Oliveira, na condição de presidente da Associação Brasileira de Antropologia (ABA), ao professor Laurent Thévenot para participar da VII Reunião de Antropologia do MERCOSUL (VII RAM), importante evento acadêmico internacional, no qual proferiu uma das mais concorridas conferências do programa e permitiu a solidificação das estradas conformadas anteriormente entre brasileiros e franceses. O título da conferência: Reconnaissances avec Paul Ricoeur et Axel Honneth na VII RAM-PortoAlegre tornar-se-ia um artigo e, posteriormente, traduzido para o português por Daniela Velasquez e Fabio Reis Mota e finalmente publicado em um dossiê organizado na revista Antropolítica em 2018. Disponível em: https://periodicos.uff.br/antropolitica/article/view/41954 Acesso em: 13 de julho de 2021
}

7 Gabriela Cuervo e Hully Falcão realizaram seus doutorados no PPGA sob a orientação de Fabio Reis Mota. 
das perspectivas teóricas, metodológicas e epistemológicas caras às diferentes tradições socioantropológicas que pertencem a essa grande rede de cooperação nacional e internacional. É dessa forma que buscamos emprestar um sentido compósito às nossas cooperações nesse ir e vir entre múltiplos focos e enfoques.

Embora os trabalhos empíricos e os campos (terrains) sejam muitas vezes diferentes, as questões teórico-metodológicas estão conectadas em torno de problemáticas relacionadas à análise das operações críticas e das provas às quais os atores são submetidos nas mais variadas situações (cívicas, morais, legais etc.) constitutivas das sociedades complexas atuais. Ao evocarem os princípios e valores que organizam os mais diversos mundos (ou "cités") 8 e configuram a vida nas grandes metrópoles contemporâneas, os indivíduos manifestam quais conflitos e argumentos legitimam as diversas demandas sociais nos contextos dos países republicanos e democráticos onde temos trabalhado.

Em meio a este processo, conferimos destaque aos dispositivos institucionais envolvidos nas reivindicações de justiça, de direito, às críticas e justificações enunciadas nas controvérsias e disputas e aos modelos de administração institucional de conflitos (KANT DE LIMA, 2008). Nossas preocupações convergentes visam determinar o lugar do Direito, dos demais mecanismos formais de administração de conflitos, das formas de qualificar e classificar os bens materiais e simbólicos que regem a vida social. Um objetivo importante dessa perspectiva consistiu em considerar as tensões e articulações decorrentes das exigências de uma gramática liberal de conformação do espaço público vis-à-vis as gramáticas locais ou sensibilidades jurídicas (GEERTZ, 2013) das próprias comunidades, que se definem por relações complexas e por distintos princípios de coordenação da ação a partir da valoração de ligações espaciais e temporais, pessoais, de proximidade, do público ou corporativas, etc. ${ }^{9}$.

Mais do que uma troca de literatura e informações, essas cooperações visaram favorecer o deslocamento de olhares e perspectivas, bem como a internacionalização das Ciências Sociais, através da interação de pesquisadores de distintos países e culturas. Diversos sociólogos, historiadores e antropólogos têm dedicado atenção para os efeitos positivos dessa "bricolage." cultural e social.

8 Ver BOLTANSKI; THÉVENOT, 1991/2020.

9 Por conta do estreitamento destes laços acadêmicos, reunimos num dossiê publicado na revista Antropolítica, n 23, 2008 - organizado por Roberto Kant de Lima e Fabio Reis Mota, intitulado Democracia, espaço público, Estado e sociedade em uma perspectiva comparada - artigos de Laurent Thévenot, José Manuel Resende (Lisboa), Maria Josefina Martinez (Buenos Aires) e Daniel dos Santos (Canadá). 


\section{OS CAMINHOS DA GOVERNANÇA PELA NORMA}

O presente dossiê é um desdobramento das atividades acadêmicas de âmbito nacional e internacional que têm animado o desenvolvimento de perspectivas e olhares cruzados sobre problemas comuns que afetam diretamente as sociedades capitalistas eocidentais contemporâneas. Nosso objetivo, desse modo, é analisar a conformação de mecanismos de controle, certificação e reconhecimento dos bens materiais e humanos nas sociedades contemporâneas através de formas de classificação que pretendem padronizar práticas e universalizar gramáticas e moralidades. O estabelecimento de regimes normativos, políticos e simbólicos característico do universo regido pela governança pela norma (THÉVENOT, 1997), apresenta-se em diferentes dimensões, seja na ciência através das dinâmicas de produção, reprodução e consagração do conhecimento ou na criação de critérios avaliativos e qualificadores; na regulação estética e de ocupação das cidades; nos modelos de qualificação de "novos mercados" (sustentáveis, étnicos, culturais etc.), entre outros. Desse modo, governar pela norma, assim como aponta Thévenot no artigo traduzido, supõe novos contornos aos modos de regulação dos Estados nacionais contemporâneos, uma vez que eles passam a conviver e concorrer com outras normatividades transnacionais constituídas alternativamente aos critérios administrativos e jurídicos circunscritos às fronteiras das Nações.

Aconformação de dispositivos avaliadores, classificadores, qualificadores e legitimadores de pesquisas, pesquisadores, mercadorias, cidadãos etc. envolve processos que compreendem a construção de acordos nem sempre simétricos e estáveis. A produção de requisitos de qualificação encontra ressonância e repercute seus efeitos através de organismos internacionais, corporações transnacionais e Estados, imprimindo lógicas avessas às múltiplas formas heterogêneas de viver e experienciar o mundo. A compreensão desses processos de padronização que se pretendem universais, do ponto de vista etnográfico, revela nuances significativas quanto às práticas e percepções dos atores acerca dos contextos e contingências em que estão inseridos. A etnografia, neste sentido, se apresenta como uma ferramenta potente para avançar em direções que permitam desvelar as diferentes articulações, adequações, composições e ressignificações diante dessas normatividades estandardizadas, além dos esquemas cognitivos e culturais pelas quais são compreendidas.

Os artigos contidos neste dossiê nos trazem agenciamentos múltiplos negociados interativamente (LATOUR, 2016; ORTNER, 2007), entre os quais circulam uma variedade de vocabulários morais que se configuram de forma situada. Os repertórios mobilizados 
pelos atores não são encarados aqui como disposições, mas como dispositivos situacionais (BOLTANSKI; THÉVENOT, 2020). A pluralidade de situações em que os atores das pesquisas aqui apresentadas se deparam exige modos distintos de adequação e ajuste, através dos quais codificam as "ações que convém" e às quais igualmente convencionam e coordenam os dispositivos de ação nos processos interativos (THÉVENOT, 2016). Essa perspectiva supõe um mundo social em constante estado de emergência, sendo os momentos críticos (BOLTANSKI; THÉVENOT, 2020) recursos analíticos valiosos, pois nos permitem apreender de forma localizada as demandas por justiça e sentidos de justo que esses movimentos da vida humana trazem à tona.

Os julgamentos, as ações e as formas de coordenação das ações intra e interpessoais são, no entanto, analisadas a partir do modo como os atores coordenam suas ações (THÉVENOT, 2016). Tal como salientam Boltanski e Thévenot (2020), as pessoas são confrontadas nas sociedades com um pluralismo radical de situações e testes cotidianos, exigindo delas um aparato de competências, justificações e argumentações para fazer valer suas demandas. A ação humana assim concebida transcorre em diferentes sequências nas quais as pessoas mobilizam competências diversas para se adequar a uma dada situação apresentada, cujos momentos públicos de disputa, conflito e controvérsia levam os próprios atores a manifestarem e evidenciarem suas razões, críticas ou justificações (BREVIGLIERI; STAVO-DEUBAGE, 1999; MOTA, 2008).

O ator, ao se confrontar com uma situação problemática, necessita colocar em evidência os procedimentos de transação através dos quais os demais atores reduzem suas diferenças, amenizam e apaziguam seus litígios e disputas, buscando, na geometria variável das formas, viabilizar acordos, perenes ou temporários, para prosseguirem em suas ações coletivas. Tais formas de acordo ou desacordo encontradas pelos atores, na vigência de suas interações, constituem, na maior parte das vezes, um refinado conjunto de argumentos e de maneiras práticas de se engajarem numa situação, sopesando seus projetos, selecionando e decidindo finalidades e objetivos, almejando constituir na cena pública um repertório aceitável de gestos para a consecução da ação visada e a articulação com seus pares numa apropriada dinâmica de cooperação e competição. Atrelada a essa dinâmica pública de justificação, de denunciação e de reivindicação, há toda uma série de modalidades de experiência e de ação que pode ser pensada, seja sob o título de regimes de proximidade (aqueles nos quais vigoram os laços de familiaridade com as coisas e com as pessoas) ou de regimes de ação pública (aqueles nos quais se enfatizam os laços públicos), como frisa Thévenot (1994). Os denominados regimes entram em relação processual quando observamos como as categorias mais gerais do Direito 
imprimem dinâmicas e produzem efeitos nas experiências mais íntimas, como as práticas de bens de consumo de determinados produtos que são qualificados e certificados sob o prisma das boas práticas, por exemplo, ou de um modo mais amplo e geral, na gestão das cidades, da ciência ou de outras instâncias da vida social moderna que estão sob o crivo da governança pela norma (THEVENOT, 1997).

Todas essas complexas e compósitas redes de conformação da "realidade", da "verdade" e das práticas humanas no mundo contemporâneo confrontam-se, como já salientamos, a esses momentos críticos, que consistem em movimentos retrospectivos, nos quais se toma distância de dada situação para produzir uma narrativa que faça sentido. Afinal, criticar nada mais é do que se afastar da ação para acessar uma posição externa, tentando considerá-la de outra perspectiva (BOLTANSKI, 2009; FALCÃO, 2019). Podemos tomar a denúncia como a materialização de um momento crítico que se refere à operação realizada pelos atores para classificarem o que consideram justo e injusto numa situação de disputa entre pessoas e grupos (BOLTANSKI; THÉVENOT, 2020; FALCÃO, 2019). Nas situações de disputa aqui apresentadas, os atores se confrontam por meio de provas (épreuve) ancoradas em repertórios morais diversos para justificar e legitimar a sua denúncia (BOLTANSKI et al, 1984). Para que o público aceite a denúncia como legítima, as justificações e críticas que a sustentam devem se basear em uma gramática comum, sendo ela mesma "produto do trabalho realizado a partir dos argumentos propostos pelos atores nas situações em que se desenvolveram" (BOLTANSKI, 2000, p. 57). No processo de busca de legitimidade, os argumentos precisam adquirir certo grau de generalidade (montée en généralité) para que os atores possam convencionar suas ações, decisões e justificativas a fim de que sejam legíveis e compreensíveis na operação dramatúrgica da vida cotidiana.

As justificações e críticas são insumos para a análise de situações de controvérsias, pois são a partir delas que os atores expõem e articulam diferentes repertórios morais que conferem suporte e legitimidade às suas demandas. As controvérsias colocam em perspectiva diferentes compreensões sobre o mundo e os argumentos produzidos para defendê-las. Nas palavras de Latour (2016, p. 43):

Quando nos aproximamos dos lugares onde são criados fatos e máquinas, entramos no meio das controvérsias. Quanto mais nos aproximamos, mais as coisas se tornam controversas. Quando nos dirigimos da vida "cotidiana" para a atividade científica, do homem comum para o de ciência, dos políticos para os especialistas, não nos dirigimos do barulho para o silêncio, da paixão para a razão, do calor para o frio. Vamos de controvérsias para controvérsias.

Essa perspectiva considera o aspecto dramatúrgico e teatral da vida cotidiana (CEFAÏ, 
2002; FREIRE; REIS, 2003). Para analisar uma controvérsia é necessário situar as falas e as categorias acionadas, descrever as expressões e emoções, narrando a dramaticidade e as práticas dos atores envolvidos, para assim dar conta das múltiplas perspectivas colocadas em jogo (FALCÃO, 2019; NARDACCHIONE, 2016). Os autores dos artigos publicados neste dossiê fazem justamente esse exercício. Vale enfatizar que a experiência emocional (HONNETH, 2003) também deve ser levada em conta quando analisamos de que formas o controle é percebido e vivenciado: quando sentimentos de insegurança e injustiça motivam o agir criativo para poder (sobre)viver a um contexto de vigilância e violência; quando embriologistas se utilizam do "feeling" obtido pela acumulação de experiências para exercer seu ofício e classificar o embrião que tem maior probabilidade de fertilizar; ou quando pesquisadores operam sistemas de controle e avaliação a partir de um saber-fazer construído entre redes epistêmicas e políticas. Colocarse à prova nas interações evidencia a ligação entre cognição e emoção, pois os movimentos da emoção contribuem para dar visibilidade à apreciação sobre o que é convencional ou não. Dessa forma,

O alargamento da perspectiva não provém apenas da diversidade dos tipos de atividade tomadas em consideração, mas igualmente de uma visão menos centrada sobre o ator humano e mais ligada às dinâmicas da relação entre esse ser e seu meio". (THÉVENOT, 2006, p. 241).

Assim, nossos esforços - seja na tradição da Antropologia Jurídica e Política da UFF, ou na vertente da Sociologia Pragmática francesa - têm se dirigido a exercitar um trabalho que nos ofereça meios de diluirmos as oposições tradicionalmente formuladas, particularmente, entre Ciências Sociais e Direito, com relação à polarização entre regra e prática. Esse ponto é particularmente crítico para o Brasil que se caracteriza pela desarticulação entre a "esfera pública" e o "espaço público" (CARDOSO DE OLIVEIRA, 2002), ou seja, entre o mundo das regras, das normas impessoais, uniformes e das interações face a face. Do mesmo modo, o sentido da regra emprestada ao nosso universo, sob o viés dogmático e inquisitorial presente no mundo jurídico brasileiro, concede formas peculiares a govervança pela norma à brasileira, como salientam Falcão, Mota e Cuervo em um artigo deste dossiê. A centralidade concedida para a autoridade legítima e competente de dizer a norma, resulta na deformação dos padrões e na particularização da aplicação e apropriação singularizada da regra (KANT DE LIMA, 2011). Nossos programas de pesquisa no Brasil e no exterior, desse modo, seguem uma via original ao considerar variações de regimes que nos convidam a um confronto com o Direito, rompendo com a divisão de trabalho clássica, segundo a qual os juristas se ocupam da normatividade formal e os sociólogos daquilo que advém das práticas. 
Dessa maneira, nossos olhares se dirigem para a compreensão das operações de julgamento e de provas, visando relacionar a política e a moral numa perspectiva weberiana, na qual as justificativas são evidenciadas a partir dos "justos motivos" ou "motivos legítimos" dos juízes e/ou dos cidadãos ordinários, na qualidade de operadores da justiça ou de manejadores das sensibilidades jurídicas locais. Para nós, o Direito e as normas são modos de investimentos que asseguram uma maior validade e perenidade às marcas de referência convencionais, diante de sua capacidade de identificar os seres e de unir-lhes qualidades informadas por gramáticas morais e políticas próprias.

Todavia, em contraposição a uma noção de bem comum habermasiano (HABERMAS, 1990), focalizada sobre a ideia do consenso, concedemos uma maior atenção à elaboração da crítica e das formas de produção do acordo e do desacordo nas situações de interação. Mais do que seguir um "eu" que se apresenta, propomos constituir um quadro, uma variedade de figurações, que não sejam reduzidas a escalas de representações, mas que possam se diferir de acordo com as animações de figurinos, nos quais os seres humanos são equipados da capacidade de ação e de interação entre os atores e os objetos que os circundam. Esse aspecto é potencialmente importante para o nosso "mundo", no qual a atividade humana exige uma competência extra para lidar com as dimensões da imprevisibilidade marcantes em nossas dinâmicas interacionais, regidas por lógicas como o "você sabe como quem está falando?" (DAMATTA, 1979) ou o da cisma (MOTA, 2018).

Esses regimes não devem ser vistos sob um prisma normativo, mas compreendidos a partir da dinâmica das interações e das formas como os atores se apropriam das "normas". Como assinala Kant de Lima (2000), as normas devem ser analisadas tanto em relação à sua substância como em relação às suas formas de apropriação - universalizadas ou particularizadas, como ocorrem no ambiente doméstico da casa e no ambiente público da rua. Neste sentido, é importante compreendermos o modo como essas operações se inscrevem em distintas lógicas ou ordens de grandeza aparentemente distintas. As argumentações e ações articulam-se e inscrevem-se num conjunto de significados e gramáticas que conferem plausibilidade à norma. Ações e justificações ganham, portanto, contornos específicos diante das distinções entre os significados emprestados às categorias mobilizadas em diferentes gramáticas e tradições jurídicas.

No Brasil, por exemplo, o domínio do público não é representado como o lugar da regra local e explícita, de aplicação universal, de todos conhecida e a todos acessível; logo, a todos aplicável igualmente e universalmente. O domínio do público - seja moral, intelectual ou até mesmo sua inscrição no espaço físico - é o lugar controlado pelo Estado, de acordo com "suas" 
regras, frequentemente de difícil acesso e, portanto, onde tudo é virtualmente permitido, até que seja proibido ou reprimido pela "autoridade". Essa espécie de categoria encarnada e, ao mesmo tempo, operador classificatório que detém não só o conhecimento do conteúdo, mas principalmente a competência para a interpretação correta da aplicação particularizada das prescrições gerais, é sempre realizada através das formas e fórmulas implícitas e do acesso privilegiado a elas (KANT DE LIMA, 2000).

Já na França, a civil law tradition construiu um publique regido por regras universais a serem seguidas por indivíduos participativos e engajados, mas genéricos. O mundo cívico francês requer que todas as relações, para serem legitimadas, sejam mediatizadas pela referência a entidades coletivas que garantam o interesse geral, tais como associações, instituições democráticas etc. (BOLTANSKI; THÉVENOT, 2020, MOTA, 2014).

Sendo assim, dispomos os artigos neste dossiê de forma a garantir um acesso a essas pluralidades de modos de lidar com a norma e suas repercussões nos modos como os atores coordenam suas ações no domínio das relações ordinárias ou no campo do Direito e/ou da ciência. Mais abaixo dispomos as linhas condutoras dos artigos ora apresentados.

\section{DISPOSITIVOS AVALIATIVOS, MULTIPLICIDADE DE AGÊNCIAS E CONTROVÉRSIAS}

Como vimos nesta introdução, a governança pela norma é um processo e um modo de operar que está presente em diferentes espaços, sendo visível, principalmente, nos sistemas de avaliação e qualificação dos objetos, da ciência dos bens de consumo, das cidades, entre outros. Esses sistemas são construídos a partir de uma moral que tenta universalizar, pautando critérios discutidos no âmbito de uma comunidade de comunicação (OLIVEIRA, 2000), configurandose, então, a partir de acordos intersubjetivos. Ainda que um sistema de avaliação seja tido como objetivo, ele operacionaliza essas diversas subjetividades, e ao mesmo tempo, é operado por elas (FALCÃO, 2019; LAMONT, 2012), evidente na conformação de regras do uso do espaço público, como na classificação de pesquisas e pesquisadores, onde as normas pautadas em um tipo de acordo são universalizadas em detrimento da variedade de formas de produzir e avaliar.

A explicitação das maneiras como normas e procedimentos são estabelecidos e consensualizados se torna tão importante quanto a abordagem de como são manejados e compreendidos por aqueles sob os quais incidem. A partir do momento em que normas, sistemas 
de classificação e guidelines se impõem, os atores inseridos em dada situação agem de maneira crítica, seja colocando à prova os conjuntos de stardards, ou reformulando-os à medida que utilizam a experiência como suporte para coordenação de sua ação. Neste sentido, os artigos aqui publicados elucidam como os processos avaliativos e valorativos são pautados também por critérios singulares, criados a partir da experiência com determinada prática avaliatória. Para o ator agir sobre ou sob esses protocolos normativos é preciso criatividade e produção de crítica para, então, criar justificações que atribuam sentido ao que está sendo colocado em prática.

O texto de Mayra Lafoz apresenta uma rica análise sobre os processos de conformação dos chamados selos de denominação de origem, identificando disputas classificatórias acerca dos critérios considerados justos e legítimos para que um produto alimentar, como os queijos, possa receber certificação. Nesse contexto, a expertise científica é mobilizada para consolidar um consenso em torno do que constitui um objeto de consumo autêntico e especial, processo no qual se consideram elementos como os ingredientes utilizados, a forma como é produzido e a região em que é fabricado. A definição e produção de valor, por conseguinte, residiria nas ideias de "artesanalidade" e distinção da mercadoria, em oposição a um quadro de referência industrial, pautado na rapidez e na larga escala produtiva.

Já Catharina Delaunay e Luís Gouveia analisam como os standards são manejados e referenciados a partir do acompanhamento de embriologistas e famílias que utilizam fecundação in vitro para gerar um embrião, também suscetível a um sistema de classificação e qualificação. Tal operação considera os estágios embrionários, tomando como referência o desenvolvimento das células e a diversidade de formas como esses estágios são significados na relação entre médicos e pacientes. Ou seja, esses critérios são manejados situacionalmente com base em "esquemas cognitivos, saberes experienciais e padrões normativos (culturais, ético-morais, religiosos, etc.)", de modo a produzir justificação para a utilização ou não dessas guidelines.

Falcão, Mota e Cuervo explicitam a construção de standards na avaliação da produção científica e da ética em pesquisa, lançando luz sobre como esses protocolos são operados situacionalmente. Além de trazerem elementos para compreendermos a conformação de plataformas (como a Lattes, a Sucupira e a Brasil) digitais, que assumem e colocam em movimento diferentes moralidades classificatórias, e que podem ser alvo de críticas pelos atores que delas utilizam e por elas são afetados. É evidente nesse trabalho, assim como nos demais, a importância de se dominar esses stardards para poder se movimentar nesses sistemas avaliativos. Esses autores, assim, colocam em perspectiva manejos e (re)significações destas modalidades de controle, a fim de dar conta de como ocorre algumas dimensões da governança científica no Brasil no cotidiano, atribuindo corpo e vida ao controle, ao descrever como diferentes atores a 
vivenciam e a performam.

Os artigos citados acima evidenciam situações nas quais a representação de que ciência só existe apartada da sociedade, e, por conseguinte, da política, é posta em xeque. O que vemos aqui é justamente a ciência sendo usada para validar um objeto ou uma ação, ou melhor, dizendo, a política conformando quais serão os objetos a serem analisados. Também é importante evidenciar as operações que podem ser feitas com a dupla, comumente pensada como um par antagônico - objetivo/subjetivo, objetividade/subjetividade - que pode ser tomada como uma forma de conceber o mundo a partir de um olhar disciplinado.

Ora, vemos neste dossiê que algo concebido e classificado como produto de um exercício objetivo é acionado a partir de múltiplas experiências e registros. O feeling classificatório de um embrião, o saber-fazer avaliativo na produção científica e ética em pesquisa ou a conformação de um selo certificador colocam à prova a pretensa objetividade das ciências e parâmetros formatados a partir dessa concepção dual da construção do conhecimento. Pares de opostos relacionados como política-ciência/técnica e subjetivo-objetivo são, assim, produtos de uma concepção homogeneizadora que se coloca como abstrata e impenetrável. Latour (2016), partindo de observação etnográfica de cientistas exercendo seus ofícios em laboratórios, concluiu que a produção do conhecimento classificado como "científico", como toda obra humana, é dotada de valores, afetos e política. O que os artigos aqui dispostos nos trazem, neste sentido, são análises atentas dos fios conformadores das normas que se pretendem neutras, objetivas e universais, a produção de conhecimento que as legitima e como são reapropriadas de forma situada pelos agentes.

\section{AS CIDADES: ENTRE USOS E CONTROLES}

Para compreensão dos fenômenos de controle e governança em cidades brasileiras contemporâneas, dispomos de um conjunto de trabalhos etnográficos que conferem destaque às modalidades de gestão da cidade em conformação em diferentes contextos, e que lançam luz sobre como atores agem sobre ou sob esses protocolos normativos. Assim também se destacam "[...] as moralidades e gramáticas envolvidas na confecção dos repertórios e vocabulários de motivações que organizam as justificações e orientam as ações" desses atores nas suas demandas por justiça, direitos "[...] e/ou mesmo de reconhecimento de seus pleitos no contexto de interação nas arenas públicas” (MOTA, 2014, p. 39). 
Esses trabalhos conferem destaque aos processos de regulação do uso dos espaços, em andamento em todas as situações analisadas, seus efeitos sobre os acessos e as práticas de diferentes conjuntos de atores, bem como as estratégias por eles acionadas em função da articulação, adequação e ressignificação das normatizações em curso.

Convidamos o leitor a observar como as etnografias urbanas que compõem o dossiê documentam a consolidação de uma compreensão muito particular dos problemas de manutenção da ordem pública, e que envolvem a intensificação da experiência de insegurança pessoal apontada por Silva (1999) como um fenômeno que incidirá sobre a gestão urbana nas últimas décadas no Brasil. Sob a narrativa da desordem e o pressuposto da presença do Estado, via policiamento, como recurso à neutralização dos conflitos (que emergirá de diferentes maneiras nesse conjunto de artigos). Esses trabalhos nos permitem visualizar as contingências das relações de força entre os diferentes segmentos e atores que se defrontam contextualmente diante das diversas formas através das quais as regras instituídas e institucionalmente garantidas são, em situação, interpretadas, aceitas, evitadas, contornadas, confrontadas etc.

Dessa maneira, a cidade nada mais é do que um contexto possível de realização da vida em conjunto, suas características intrínsecas refletindo uma ordem moral caracterizada pelo atravessamento entre diferentes ordens de grandeza e, portanto, um rico contexto de análise dos processos em curso. O contexto de um capitalismo mundializado, neste sentido, é acompanhado pela intensificação dos processos de urbanização, incidindo, sobretudo, na redefinição de um sentido de cidade.

Aos interesses de uma socioantropologia urbana da moral, se destaca nas cidades contemporâneas uma condição de copresença marcada pela coexistência de uma pluralidade de ideais de bem. Essa pluralidade é, por um lado, uma realidade sobre a qual se define a experiência citadina em si mesma e, por outro, caracterizada, em sua conformação, pelas desigualdades de acesso à cidade produzidas no interior do próprio sistema de produção (inclusive do espaço) em dado momento histórico. Assim sendo, a grandeza e a ruína da cidade se encerram em sua conformação diversa, dinâmica e iminentemente conflitiva.

Ao mesmo tempo, no interior de um processo de consolidação de uma governança por objetivos (THÉVENOT, 1997, 2019, 2015b, 2020), podemos observar os modos como os conflitos serão objeto de intervenção através das modalidades de gestão dos espaços urbanos na atualidade. A normatização da vida urbana se dará, segundo Breviglieri (2013), através da elaboração de um espaço defensivo e que implica em uma demanda urgente de garantias sobre sua reformulação e seu bom uso. Essa gestão da ordem pública se exime do papel de dispositivo democrático de conciliação pelo diálogo com os desejos racionais dos habitantes, como 
destaca o autor em artigo intitulado "Uma brecha crítica na "cidade garantida"? Espaços intermediários e arquiteturas de uso" (publicado traduzido neste número da Antropolítica)

Apontando para um processo de fragilização do Estado de direito, Cheyns e Thévenot (2019) atestam para os atravessamentos locais produzidos por instâncias não estatais de regulação. Um novo padrão, que desloca a regulamentação legal dos Estados-nação para as mãos de atores econômicos e sociais supraestatais (BOLTANSKI; THÉVENOT, 2020). Do mesmo modo, as questões locais são invisibilizadas em favor de um sentido de cidade que é exterior a uma conformação urbana particular, que a subordina, incidindo sobre uma forma de cidadania paradoxal, porque alijada de um sentido de bem comum.

Essa cidade garantida (BREVIGLIERI, 2013) é gerida em função da administração do caos, tendo como objetivo primordial a promoção de um ordenamento dos espaços públicos com a promessa de uma harmonia falaciosa. Os conflitos entre as moralidades em coexistência, as desigualdades de acesso a serviços, à infraestrutura ou a condições de vida e moradia satisfatórias são subordinados a uma gramática liberal que visa, exclusivamente, à produção de índices favoráveis, de acordo com os objetivos preestabelecidos e, nesse contexto, articulados a uma lógica mercantil de cidade. Deste modo, essa modalidade de gestão está alienada da compreensão dos reordenamentos sociais que refletem a configuração do espaço urbano.

A perspectiva de análise que nos inspira e atravessa as análises que compõem este dossiê entende esses confrontos como situações de prova, que tendem a mobilizar, em função da sua resolução, um horizonte comum de referências normativas e de expectativas, sendo propícios aos reordenamentos e rearranjos (BOLTANSKI; THÉVENOT; 2020). Essas disputas, longe de serem analisadas como fenômenos disruptivos, são percebidas como oportunidades nas quais os atores podem “[...] argumentar, ponderar, ou buscar um 'princípio superior comum' que goze de relativa aceitabilidade pública" (CORRÊA; DIAS, 2016, p. 82, grifo nosso), vislumbrando um horizonte possível.

Por outro lado, Boltanski e Thévenot (2020) partem do pressuposto de que a cidade se caracteriza por um horizonte de acordo, o que, para Freire (2010, p. 137, grifo nosso), é colocado em questão pelos resultados das pesquisas desenvolvidas no cenário da Região Metropolitana do Rio de Janeiro:

[...] o sentimento de insegurança das camadas médias da RMRJ, por ter maior visibilidade no espaço público, fundamenta - ou consolida - a construção de estigmas (GOFFMAN, 1975) e de rótulos (BECKER, 2008) a respeito de segmentos pobres da RMRJ.

Em consonância com Silva, a autora destaca que "[...] o pressuposto de universalidade 
de acesso ao espaço público não caracteriza o cenário das metrópoles brasileiras" (p. 135), culminando em processos de desumanização de determinados grupos sociais. Os trabalhos que aqui reunimos nos remetem, assim, à pergunta em torno de quais são os horizontes comuns possíveis vislumbrados pelos citadinos metropolitanos brasileiros e em que medida os processos observáveis em nosso contexto se relacionam com àqueles apontados pela sociologia e antropologia pragmática da crítica.

Ao longo das últimas décadas, observamos a exacerbação dos conflitos instaurados no interior do desenvolvimento do próprio capitalismo. Fenômeno que estimulará, no Brasil, a proeminência de formas de sociabilidade urbana nas quais " [...] a força física [...] deixa de ser um meio de ação regulado por fins que se deseja atingir, para se transformar em um princípio de coordenação (um "regime de ação") das práticas" (SILVA, 2010, p. 286). Se a violência (que denomina essa forma de sociabilidade) é expressão da ausência da capacidade de agir em comum (BOLTANSKI; THÉVENOT, 2020), cabe refletir de que maneira os arranjos vêm sendo estabelecidos para dar conta do (des/re)ordenamento urbano contemporâneo.

Freire (2010) aborda o regime de desumanização como uma forma de coordenação que sustenta a sociabilidade em seu espaço de análise. Essa gramática se articularia em torno não da dignidade dos seres, mas sim do pertencimento a uma humanidade comum, assim, "[...] os seres com 'humanidade questionada' têm uma voz que não é reconhecida como legítima no espaço público" (p. 131, grifo do autor). Desse modo, a autora aponta para um ordenamento da coisa pública instaurado em um arranjo excludente entre o Estado e os grupos sociais com maior competência para tornar públicos os seus problemas.

O trabalho de Apoena Mano e Palloma Menezes, bem como o de Talitha Mirian do Amaral Rocha, indicam estados de grandeza (ou pequenez, no caso) que colocam em questão o princípio de dignidade comum de dois conjuntos de atores: os moradores da favela Santa Marta, no Rio de Janeiro, e os mototaxistas que atuam no Morro do Estado, em Niterói, respectivamente. Mano e Menezes discutem os modos como os dispositivos de vigilância compõem o cenário de experiências vividas na favela de Santa Marta, sejam eles operacionalizados por agentes de segurança pública ou traficantes no contexto de ocupação do território. Além do mais, abordam os modos como os moradores mobilizam criativamente dispositivos de (contra)vigilância, dando novas roupagens às dinâmicas sociotécnicas que compõem a gestão desse espaço em favor da sua habitabilidade e da publicização dos seus problemas no contexto de "pacificação" das favelas. Rocha apresenta as práticas de repressão da atividade profissional dos mototaxistas e coloca em questão o direito deles à cidade. 
Em ambos os territórios, os arranjos ${ }^{10}$ que permitem a constituição de um acordo contingente capaz de fundamentar um compromisso, e que está na base dos modos de regulação (pela repressão) do "problema favela", bem como do trabalho dos mototaxistas, responde a uma conveniência recíproca localizada, em detrimento de um bem geral, mas que exclui os atores diretamente envolvidos (e cujas práticas e condição de vida são tomadas como meros objetos de intervenção). Assim, Mano, Menezes e Rocha nos remetem a "[...] uma metafísica [...] orientadora de uma gramática de justificação pública que busca extrair certos seres de uma humanidade comum" (FREIRE, 2010, p. 120).

Articulando um modelo de gestão assentado sobre um princípio superior comum que prioriza o privado em detrimento do público (BREVIGLIERI, 2013), ao processo de dessolidarização associado ao achatamento do conflito socia ${ }^{11}$ (SILVA, 2010) e a uma gramática de desumanização (FREIRE, 2010), vislumbramos alguns indicativos capazes de elucidar o "ambiente cognitivo e moral" (p. 121) a partir do qual esses citadinos orientam suas ações cotidianas.

Os textos de Ana Paula Rocha de Oliveira e Julia Galli O’Donnell, assim como o de Manuela Vieira Blanc, nos permitem, por outro lado, visualizar os processos de estandardização em andamento em dois outros conjuntos de situações: aquelas que envolvem o processo de reorganização do Carnaval de rua carioca e aquelas que dizem respeito à gestão de um bairro central da capital do estado do Espírito Santo, incidindo sobre o associativismo comunitário. Ambos os trabalhos lançam luz aos reordenamentos em processo de consolidação, às estratégias de articulação e às tentativas de ressignificação das normatizações em curso. Ao mesmo tempo, apontam para os atravessamentos experimentados pelos atores posicionados em estados inferiores no interior dessa ordem de grandeza em suas tentativas de se fazer ouvir, ainda mais críticos em processos que escapam à justificação ${ }^{12}$, situações de disputa fundamentadas em uma gramática liberal de interesses individuais e, portanto, em nada comprometidas com uma gramática plural de bens comuns.

Observamos in loco os modos como os processos deliberativos participativos operam no plano da administração dos conflitos, se isentando do compromisso de contribuir abertamente para a realização do bem comum ao promover uma civilidade liberal através da qual deve se expressar um "espaço de opiniões" na escala do projeto (THÉVENOT, 2008). Ambos os

10 Ver BOLTANSKI; THÉVENOT, 2020.

11 Fenômeno denunciado pelo autor quanto à gestão da criminalidade na cidade do Rio de Janeiro, mas que o próprio abre a possibilidade de verificação empírica em diferentes cidades brasileiras.

12 Ver BOLTANSKI; THÉVENOT, 2020. 
trabalhos, o de Mano e Menezes e o de Rocha, apontam para as diferentes posições ocupadas pelos atores envolvidos e para uma tendência à fragmentação em torno de interesses particularizados que incide negativamente sobre sua capacidade de agir em comum. Esses atores veem, desse modo, cerceadas as suas possibilidades de ação, tendo ainda enfraquecido o seu potencial de conformação enquanto um público capaz de publicizar seus problemas. Como pano de fundo, observamos a questão da insegurança urbana fundamentando a emergência de demandas pelo controle repressivo do uso dos espaços e o questionamento da humanidade comum dos atores que por eles circulam.

Para Breviglieri (2013), a causa da angústia no viver urbano não corresponde à proliferação dos maus ordinários da cidade, mas à profunda ambivalência do próprio cenário: esse espaço diverso que deveria estimular o desenvolvimento de uma maior tolerância. Os trabalhos que aqui reunimos reforçam essa premissa, ao mesmo tempo que nos permitem refletir sobre os efeitos desse processo em contextos como o das cidades brasileiras, marcadas pela [...] “inexistência de um 'mundo comum' e para a impossibilidade de viabilizá-lo" (FREIRE, 2010, p. 134, grifo do autor).

As traduções que compõe esta edição da revista Antropolítica (os artigos de Laurent Thévenot, que integram o nosso dossiê, e o artigo de Marc Breviglieri, publicado nesta mesma edição da revista) nos conferem importantes indicativos para a análise dos dados empíricos aqui reunidos, bem como inspiram reflexões quanto às especificidades do contexto urbano contemporâneo brasileiro. Pensar em gestão urbana é refletir sobre os seus efeitos sobre a condição citadina e os modos de vida urbanos que a partir dela se desenvolvem e, portanto, a sua relação com modos de agir em comum.

Esperamos que as leitoras e os leitores desta coletânea percebam que as análises aqui empreendidas evidenciam os dispositivos, a tessitura e a recomposição das novas formas de regulação, controle e certificação dos objetos e pessoas na contemporaneidade em diferentes situações etnográficas no Capitalismo em processo de reconfiguração no século XXI. 


\section{REFERÊNCIAS}

1. BOLTANSKI, L. De la critique: précis de la sociolgie de l'émancipation. Paris: Gallimard, 2009.

2. BOLTANSKI, L.; DARRÉ, Y.; SCHILTZ, M. La dénonciation. Actes de la recherche en sciences sociales, n. 51, mars, 1984. Disponível em: https://www.persee.fr/doc/ arss_0335-5322_1984_num_51_1_2212. Acesso em: 21 jun. 2021.

3. BOLTANSKI, L.; THÉVENOT, L. A justificação: sobre as economias da grandeza. Rio de Janeiro: Editora UFRJ, 2020.

4. BREVIGLIERI, M. Une brèche critique dans la ville garantie? Espaces intercalaires et architectures d'usage. In: LANZA, E. C.; PATTARONI, L.; PIRAUD, M.; TIRONE, $B$. Le quartier des Grottes à Genève: de la différence urbaine. Genève: MétisPresses, 2013.

5. BREVIGLIERI, M.; STAVO-DEBAUGE, J. Le geste pragmatique de la sociologie française. Autour des travaux de Luc Boltanski et Laurent Thevénot. Antropolitica: Revista Contemporânea de Antropologia, n. 7, p. 7-22, 1999. Disponível em: $\quad$ https://drive.google.com/file/d/0B9HwgBRe_UoIbU9yUjkwNTQyWnM/ view?resourcekey=0-pXA80HaK2gxkChveMARt3Q. Acesso em: 18 jun. 2021.

6. BREVIGLIERI, M.; DIAZ, P.; NARDACCHIONE, G. L'experiénce latino-américaine de la sociologie pragmatique francofone. Revue Sociologies, 2017. Disponível em: https://journals.openedition.org/sociologies/6174. Acesso em: 21 jun 2021.

7. CARDOSO DE OLIVEIRA, L. R. Desvendando evidências simbólicas: compreensão e conteúdo emancipatório da antropologia. 1. ed. Rio de Janeiro: Editora UFRJ, 2018.

8. CARDOSO DE OLIVEIRA, L. R. Direito legal e insulto moral: dilemas da cidadania no Brasil, Quebec e EUA. Rio de Janeiro: Relume Dumará, 2002.

9. CEFAÏ, D. “Qu'est-ce qu'une arène publique?”. In: CEFAÏ, D.; JOSEPH, I. (org.). L'héritage du pragmatisme. Conflits d'urbanités et épreuves de civisme. Paris: Editions de l'Aube, 2002

10. CHEYNS, E.; THÉVENOT, L. Le gouvernement par standards de certification consentement et plaintes des communautés affectées. La Revue desdroits de l'homme, n. 16, p 1-33, 2019. Disponível em: https://journals.openedition.org/revdh/6843. Acesso em: 21 jun. 2021.

11. CORREAA, D. S.; DIAS, R. C. A crítica e os momentos críticos: de la justification e a guinada pragmática na sociologia francesa. Mana, Rio de Janeiro, v. 22, n. 1, p. 67-99, 2016. Disponível em: https://www.scielo.br/j/mana/a/ CRrYxGGY9G7zGsM7RGSfsdq/?lang=pt. Acesso em: 07 jun. 2021. 
12. DAMATTA, R. Você sabe com quem está falando? Um ensaio sobre a distinção entre indivíduo e pessoa no Brasil. In: DAMATTA, R. Carnavais, Malandros e Heróis. Rio de Janeiro: Zahar, 1979. p. 139-193.

13. FALCÃO, H. G. "Burocracia da ética": uma análise antropológica sobre a regulação da prática da pesquisa científica no Brasil. 2019. 217 f. Orientador: Fabio Reis Mota Tese (Doutorado em Antropologia) - Universidade Federal Fluminense, Niterói, 2019. Disponível em: http://ppgantropologia.sites.uff.br/?page_id=4243. Acesso em: 19 jun. 2021.

14. FREIRE, J. Agir no regime de desumanização: esboço de um modelo para análise da sociabilidade urbana na cidade do Rio de Janeiro. Dilemas: Revista de Estudos de Conflito e Controle Social, Rio de Janeiro, v. 3, n. 10, p. 119-142, 2010. Disponível em: https://revistas.ufrj.br/index.php/dilemas/article/view/7186. Acesso em: 21 jun. 2021.

15. FREIRE, J.; REIS, G. Participação e arenas públicas: um quadro analítico para pensar os conselhos municipais setoriais e os fóruns de desenvolvimento local. Cadernos Metrópole, São Paulo, v. 1, p. 75-102, 2003. Disponível em: https://revistas.pucsp.br/ index.php/metropole/article/view/9200. Acesso em: 25 maio 2019.

16. GEERTZ, C. O saber local: novos ensaios em antropologia interpretativa. Petrópolis: Vozes, 2013.

17. HABERMAS, J. Mudança estrutural da esfera pública. São Paulo: Fundação Editora UNESP, 1990.

18. HONNETH, A. Luta por reconhecimento: a gramática moral das lutas sociais. São Paulo: Editora 34, 2003.

19. KANT DE LIMA, R. Carnavais, malandros e heróis: o dilema brasileiro do espaço público. In: GOMES, L. G.; BARBOSA, L.; DRUMMOND, J. A. (org.). O Brasil não é para Principiantes. Rio de Janeiro: FGV, 2000. p. 105-124.

20. KANT DE LIMA, R. Ensaios de antropologia e de direito: acesso à justiça e processos institucionais de administração de conflitos e produção da verdade jurídica em uma perspectiva comparada. Rio de Janeiro: Lúmen Júris Editora, 2008.

21. LAMONT, M. Toward a Comparative Sociology of Valuation and Evaluation. Annual Review of Sociology, v. 38, p. 201-221, 2012.

22. LATOUR, B. Cogitamus: seis cartas sobre as humanidades científicas. São Paulo: Editora 34, 2016.

23. MOTA, F. R. Deslocamentos, movimentos e engajamentos: as formas plurais da ação humana na perspectiva de Laurent Thévenot. Antropolítica: Revista Contemporânea de Antropologia, Niterói, n. 23, p. 222-234, 2008. Disponível em: https:/app.uff.br/ riuff/handle/1/12031. Acesso em: 14 jun. 2021.

24. MOTA, F. R. Cidadãos em toda parte ou cidadãos à parte? Demandas de direitos e 
reconhecimento no Brasil e na França. Rio de Janeiro: Consequência Editora, 2014.

25. MOTA, F. R. Do indivíduo blasé aos sujeitos cismados: reflexões antropológicas sobre as políticas de reconhecimento na contemporaneidade. Antropolítica: Revista Contemporânea de Antropologia, Niterói, n. 44, p. 124-148, 2018. Disponível em: https://periodicos.uff.br/antropolitica/article/view/41959. Acesso em: 14 jun. 2021.

26. NARDACCHIONE, G. Laurent Thévenot, autor de una sociología heterodoxa en la Francia del siglo XX. In: THÉVENOT, L. La acción en plural: una introducion a la sociologia pragmática. Buenos Aires: Siglo Veintiuno Editores, 2016.

27. OLIVEIRA, R. C. de. O lugar (e em lugar) do método. Idéias, Campinas, v. 1/2, p. 174178, 1996. Disponível em: http://dan.unb.br/images/doc/Serie190empdf.pdf. Acesso em: 14 jun. 2021.

28. ORTNER, S. Poder e projetos: reflexões sobre a agência. In: GROSSI, M. P. et al. (org.). Conferências e diálogos: saberes e práticas antropológicas. Blumenau: Nova Letra, 2007.

29. SILVA, L.A. M. "Violência urbana", segurança pública e favelas: o caso do Rio de Janeiro atual. Caderno CRH, Salvador, v. 23, n. 59, p. 283-300, maio/ago. 2010. Disponível em: https://www.scielo.br/j/ccrh/a/GKPh5kRxjqKDHpWjYdPn3pn/?lang=pt. Acesso em: 21 jun. 2021.

30. SILVA, L. A. M. Criminalidade violenta: por uma nova perspectiva de análise. Revista de Sociologia Política, Curitiba, v. 13, p. 115-124, 1999. Disponível em: https://www. scielo.br/j/rsocp/a/6W7KgY6yLBSJxtrrV7BycCs/?lang=pt. Acesso em: 21 jun. 2021.

31. THÉVENOT, L. A new calculable global world in the making: governing through transnational certification standards. In: MENNICKEN, A.; SALAIS, R. (ed.). The New Politics of Numbers: Quantification, Administrative Capacity and Democracy. London: Palgrave Macmillan, 2019.

32. THÉVENOT, L. Autorités à l'épreuve de la critique. Jusqu'aux oppressions du 'gouvernement par l'objectif. In: FRERE, B. Le tournant de la théorie critique. Paris: Desclée de Brouwer, 2015. p. 216-235.

33. THÉVENOT, L. Sacrifices et bénéfices de l'individu dans un espace public libéral. Cahiers d'éthique sociale et politique, n. 5, p. 68-79, 2008. Disponível em: https:// ixtheo.de/Record/164634927X. Acesso em: 21 jun. 2021.

34. THÉVENOT, L. Un gouvernement par les normes: Pratiques et politiques des formats d'information. In: CONEIN, B.; THÉVENOT, L. (ed.). Cognition et information en société. Paris: Ed. de l'EHESS, 1997. p. 205-241. (Raisons Pratiques 8).

35. THÉVENOT, L. La acción en plural: una introducion a la sociologia pragmática. Buenos Aires: Siglo Veintiuno Editores, 2016.

36. THÉVENOT, L. Le régime de familiarité: Des choses en personnes. Genèses, n. 17, 
p.72-101, 1994. Disponível em: https://www.persee.fr/doc/genes_1155-3219_1994_ num_17_1_1262. Acesso em: 19 jun. 2021.

\section{Hully Guedes Falcão}

Pós-doutoranda pelo Programa de Pós-graduação em Informação e Comunicação em Saúde da Fundação Oswaldo Cruz. Doutora em Antropologia pelo Programa de Pós-graduação em Antropologia da Universidade Federal Fluminense. ID ORCID: https://orcid.org/0000-00021932-3104. E-mail: hullyfalcao@gmail.com. Colaboração: pesquisa bibliográfica, seleção e sistematização de artigos; redação da apresentação.

\section{Fabio Reis Mota}

Professor Adjunto do Programa de Pós-graduação em Antropologia da Universidade Federal Fluminense. Coordenador do Núcleo Fluminense de Estudos e Pesquisa, pesquisador do Instituto Nacional de Administração de Conflitos. Doutor em Antropologia pelo Programa de Pós-graduação em Antropologia da Universidade Federal Fluminense. ID ORCID: https://orcid. org/0000-0001-7883-8258. E-mail: reismota@gmail.com. Colaboração: pesquisa bibliográfica, seleção e sistematização de artigos; redação da apresentação.

\section{Manuela Vieira Blanc}

Doutora em Sociologia Política pela Universidade Estadual do Norte Fluminense Darcy Ribeiro. Coordenadora do Grupo de Pesquisa Cidades, Espaços Públicos e Periferias e do Projeto Cep 29: Núcleo capixaba de estudos da experiência humana em meio urbano. Professora do Departamento de Ciências Sociais da Universidade Federal do Espírito Santo. ID ORCID: http://orcid.org/0000-0003-0595-7875. E-mail: manu_uenf@yahoo.com.br. Colaboração: pesquisa bibliográfica, seleção e sistematização de artigos; redação da apresentação.

Gabriela de Lima Cuervo

Professora I de Sociologia da Secretaria de Educação do Rio de Janeiro. Doutora em Antropologia pelo Programa de Pós-graduação em Antropologia da Universidade Federal Fluminense. ID ORCID: https://orcid.org/0000-0003-0766-0805. E-mail: bicuervo@gmail.com. Colaboração: pesquisa bibliográfica, seleção e sistematização de artigos; redação da apresentação. 